\title{
ANALISIS BRAND EQUITY DAN KEPUTUSAN PEMBELIAN ( STUDI PADA PEGADAIAN SYARIAH DI KOTA PALEMBANG)
}

\author{
Nedi Yansah \\ Fakultas Ekonomi Universitas Sriwijaya \\ nediyansah@gmail.com \\ Zakaria Wahab \\ Fakultas Ekonomi Universitas Sriwijaya \\ zkwahab@yahoo.com \\ H. Muchsin Saggaf Shihab \\ Fakultas Ekonomi Universitas Sriwijaya \\ muchsin.shihab@bakrie.ac.id
}

\begin{abstract}
ABSTRAK
Penelitian ini bertujuan untuk menganalisis pengaruh brand positioning dan sales promotion terhadap brand equity dan keputusan pembelian konsumen. Ada pun yang menjadi studi kasus penelitian ini adalah Pegadaian Syariah di Kota Palembang. Data penelitian ini terdiri dari data primer dan data sekunder. Data primer diperoleh dengan menggunakan kuesioner, yang dibagikan pada responden menggunakan teknik convenience sampling. Sampel penelitian ini berjumlah 100 responden. Data sekunder diperoleh dari berbagai sumber sepertijurnal, buku dan publikasi terkait lainnya. Teknik analis is pada penelitian mengunakan teknik Structural Equation Modeling (SEM). Hasilnya menunjukkan bahwa brand positioning memiliki pengaruh positif dan signifikan terhadap brand equity; sebaliknya sales promotion memililki pengaruh negatif. Selanjutnya, ditemukan bahwa brand positioning tidak berpengaruh pada keputusan pembelian, sales promotion memiliki dampak negatif dan signifikan terhadap keputusan pembelian. Brand equity tidak berpengaruh terhadap keputusan pembelian. Disarankan agar perusahaan lebih memperhatikan pembentukan brand positioning dengan menerapkan standarisasi pelayanan, terutama yang berkaitan dengan kecepatan, kenyamanan, dan fleksibilitas pelayanan. Perusahaan juga harus meningkatkan kompetensi karyawan dasi sisi pemahaman syariah. Sebaliknya, dalam hal kegiatan promosi penjualan perusahaan harus melakukan evaluasi yang mendalam, dikarenakan kegiatan promosi penjualan yang dilaksanakan selama ini terbukti kurang efektif mendorong keputusan pembelian.
\end{abstract}

\section{Kata Kunci :}

Brand Positioning, Sales Promotion, Brand Equity, Keputusan Pembelian

\begin{abstract}
This study aims to analyze the influence of brand positioning and sales promotion on brand equity and consumer purchasing decisions. Pegadaian Syariah Palembang City was taken as a case stud. Both primary and secondary data were obtained. Secondary data were obtained from various sources ssuch as journals, books and other related publications. Primary data were obtained by distributing to the target respondents. Using a convenience sampling technique, a total sample of 100 respondents were obtained. Structural Equation Modeling (SEM) analysis tecahnique was employed. The results show that brand positioning had a posoitve and significant effect on brand equity and sales promotion had adverse effect. Further, it was found that brand positioning has no effect on purchasing decisions, sales promotion has a negative and significant impact on purchasing decisions. Brand equity has no effect on purchasing decisions. It is suggested that the comapny should the company pay more attention to the establishment of brand positioning by applying service standardization, especially related to the speed, convenience, and flexibility of service. The company should increase the competence of of employees about sharia khowledge. Otherwise, in terms of sales promotion activities companies should be evaluated, because of sales promotion programs were not effective.
\end{abstract}

Keywords :

Brand Positioning, Sales Promotion, Brand Equity, Purchase Decision 


\section{PENDAHULUAN}

Keputusan pembelian menurut Kotler dan Keller (2009) adalah proses konsumen dalam menentukan pembelian produk atau jasa di antara beberapa alternatif yang tersedia. Konsumen dalam proses menentukan keputusannya salah satunya dipengaruhi oleh rangsangan pemasaran. Rangsangan pemasaran terkait dengan bauran pemasaran (marketing mix), yang terdiri dari strategi produk ( $p r o d u c t)$, strategi harga (price), strategi distribusi (place), dan strategi promosi (promotion).

Penelitian ini bertujuan untuk menelisik lebih dalam terkait dengan strategi produk dan strategi promosi. Adapun bentuk strategi produk yang akan dikaji adalah hubungan strategi pemosisian merek (brand positioning) dalam meningkatkan ekuitas merek (brand equity) dan mempengaruhi keputusan pembelian konsumen (consumer purchase decision). Sedangkan bentuk strategi promosi yang akan diungkapkan adalah hubungan promosi penjualan (sales promotion) dalam meningkatkan ekuitas merek dan mempengaruhi keputusan pembelian konsumen.

Terdapat beberapa kajian terkait hubungan antara brand positioning, sales promotion, brand equity dan keputusan pembelian. Kusno et.al (2007) menemukan bahwa terdapat hubungan yang kuat antara brand positioning dan brand equity. Lebih jauh dijelaskan bahwa terdapat hubungan kausal positif dan signifikan antara brand positioning terhadap dimensi yang terdapat dalam brand equity, diantaranya brand awareness, brand associations, perceived quality, dan brand loyalty. Selain itu, lebih jauh Rodrigues et.al (2013) dan Chen et. al (2016) menemukan bahwa brand positioning adalah strategi produk yang paling berpengaruh terhadap brand loyalty, yang merupakan dimensi penting dalam brand equity.

Maharani, et.al (2014) dan Jatmiko et.al (2015) menjelaskan bahwa brand positioning berpengaruh signifikan terhadap keputusan pembelian. Penelitian Qi et.al (2013) juga menemukan bahwa brand positioning berpengaruh terhadap brand equity. Brand positioning dan diferensiasi merek dapat digunakan oleh seorang manajer merek untuk meningkatkan brand equity produk atau jasa perusahaan.

Terkait hubungan sales promotion, juga terdapat beberapa kajian diantaranya; Surahmat et.al (2008) dan Florence et.al (2011) 
menemukan sales promotion pengaruhnya negatif terhadap brand equity. Mongilala (2010) dan Octaria et.al (2015) menemukan hasil yang sebaliknya, yaitu sales promotion berpengaruh signifikan terhadap brand equity. Penelitian Salelaw, et.al (2016), lebih jauh menerangkan pengaruh positif sales promotion terhadap brand equity, terutama pada dimensi brand awareness, brand associations, dan brand perceived quality.

Surahmat et.al (2008) dan Octaria et.al menemukan sales promotion berpengaruh tidak signifikan terhadap keputusan pembelian. Namun sebaliknya, Fauziah (2015) menemukan sales promotion berpengaruh signifikan terhadap keputusan pembelian. Demikian juga Shreshta (2015) menemukan bahwa sales promotion berpengaruh positif terhadap keputusan pembelian. Adapun bentuk sales promotion yang menjadi faktor kunci berupa diskon, kupon, sampel, dan point of sales.

Kajian terkait hubungan brand equity diantaranya; Surahmat et.al (2008), Octaria et. al.(2015) dan Jatmiko et.al (2015) menemukan bahwa terdapat hubungan yang kuat antara brand equity dan keputusan pembelian.
Vukasovic (2013), Heidarian et.al (2015), dan Siali et.al(2016) juga menemukan temuan yang sama. Riset Nigam, et.al (2011) menjelaskan bahwa brand equity yang kuat memungkinkan perusahaan mempertahankan pelanggannya lebih baik, melayani kebutuhan pelanggan dengan lebih efektif, dan meningkatkan keuntungan. Siali et.al (2016) juga menerangkan bahwa elemen brand equity yang paling dominan mempengaruhi keputusan pembelian adalah brand perceived quality.

Dari beberapa penelitian di atas disimpulkan bahwa semua penelitian menemukan hasil yang sama terkait hubungan brand positioning, brand equity dan keputusan pembelian. Namun beberapa penelitian berbeda hasilnya terkait pengaruh sales promotion terhadap brand equity dan keputusan pembelian. Selain itu juga, penelitian ini akan berupaya mengungkapkan hubungan tidak langsung antara brand positioning dan keputusan pembelian dengan brand equity sebagai variabel intervening. Peneliti belum menemukan penelitian terkait dengan hal ini.

Penelitian terkait brand positioning, sales promotion, brand equity, dan keputusan pembelian relevan untuk dilakukan di 
Pegadaian Syariah Simpang Patal. Adapun yang mendasarinya adalah semakin kompetitifnya persaingan dalam bisnis gadai dan fenomena kinerja operasional Pegadaian Syariah Simpang Patal yang cenderung stagnan.

Persaingan dalam bisnis gadai semakin kompetitif dengan terbitnya peraturan Otoritas Jasa Keuangan (OJK) Nomor 31 Tahun 2016 terkait Usaha Pergadaian. Berdasarkan release Harian Berita Sore, sampai akhir tahun 2016 sudah ada 2.200 perusahaan yang mengajukan izin usaha bisnis gadai ke OJK. Dibukanya keran bisnis gadai bagi swasta tentu akan berdampak pada Pegadaian, termasuk di dalamnya Pegadaian Syariah, yang selama ini memonopoli bisnis gadai.

Demikian juga di Kota Palembang kondisi persaingan sudah mulai tampak. Beberapa bank syariah, seperti Bank Mandiri Syariah, Bank BRI Syariah, Bank Mega Syariah, Bank Danamon Syariah, dan Bank Sumsel Syariah sudah terlebih dahulu membuka layanan gadai sistem syariah. Terbukanya ruang swasta untuk masuk ke bisnis gadai akan semakin meningkatkan persaingan bisnis gadai di Kota Palembang.
Kondisi persaingan inilah yang seyogyanya menjadi perhatian manajemen Pegadaian Syariah Simpang Patal. Manajemen harus menyiapkan strategi untuk menyambut persaingan yang semakin keras. Dalam konteks penelitian ini adalah merancang strategi brand positioning dan strategi sales promotion untuk meningkatkan ekuitas merek perusahaan. Lebih lanjut diharapkan mampu mendorong konsumen bertransaksi di Pegadaian Syariah Simpang Patal.

Kinerja pembiayaan Pegadaian Syariah Simpang Patal akhir-akhir ini cenderung mengalami stagnasi, bahkan beberapa tahun belakang cenderung terus menurun. Kondisi ini terlihat pada tingkat pertumbuhan penyaluran pembiayaan yang terus turun. Pada tahun 2013 tingkat pertumbuhan omset pembiayaan dari tahun sebelumnya adalah sebesar 72.2 persen. Namun pada tahun 2016 tingkat pertumbuhannya daritahun 2015 hanya sebesar 13.4 persen. Lebih lengkap perhatikan Tabel 1 berikut ini: 
Tabel 1. Kine rja Pembiayan Pegadaian Syariah di Kota Palembang

\begin{tabular}{|c|c|c|c|}
\cline { 1 - 1 } Uraian & \multirow{2}{*}{$\begin{array}{c}\text { Omset } \\
\text { Pembiayaan }\end{array}$} & Pertumbuhan & Selisih \\
\cline { 1 - 1 } Tahun & Milyar) & $(\%)$ & $(\%)$ \\
\hline 2012 & 54.6 & 0 & 0 \\
\hline 2013 & 94 & 72.2 & 72.2 \\
\hline 2014 & 110 & 17.0 & -55.2 \\
\hline 2015 & 125 & 13.6 & -3.4 \\
\hline 2016 & 141.7 & 13.4 & -0.2 \\
\hline
\end{tabular}

Sumber: MIS Pegadaian, data diolah

Trend penurunan ini seyogyanya menjadi perhatian bagi manajemen Pegadaian Syariah Simpang Patal. Manajemen perlu mengevaluasi strategi yang diterapkan selama ini. Dalam konteks kajian ini, apakah strategi brand positioning dan kegiatan sales promotion yang diterapkan mampu mendorong penguatan brand equity perusahaan. Selain itu juga akan digali apakah strategi brand positioning dan kegiatan sales promotion yang dilaksanakan selama ini masih efektif untuk mendorong nasabah memilih Pegadaian Syariah Simpang Patal.

Pegadaian Syariah, terkait brand positioning, telah mengkomunikasikan ke benak konsumen beberapa positioning statement (pernyataan posisi). Adapun yang menjadi main statement (pernyataan utama) adalah Pegadaian Syariah adalah solusi tepat kebutuhan dana cepat sesuai syariah dan Pegadaian Syariah benar caranya berkah hasilnya. Sedangkan yang menjadi program statement di antaranya Pegadaian Syariah adalah BUMN (Badan Usaha Milik Negara), syarat mudah, proses aman, cepat, mudah, setoran angsuran pinjaman ringan, dan Pegadaian Syariah terpercaya.

Begitu juga terkait dengan sales promotion, Pegadaian Syariah telah menjalankan berbagai program diantaranya program undian Kemilau Emas, program hadiah langsung, cashback biaya administrasi, bebas bea materai, pembagian merchandise, diskon jasa titipan (ujroh), voucher pulsa, seminar investasi emas, seminar wirasusaha, seminar pembiayaan haji, melakukan open table di berbagai pusat keramaian, bazaar emas lelang dan literasi produk ke komunitas.

Berdasarkan latar belakang tersebut, maka tujuan penelitian ini adalah (1) mengetahui dan menjelaskan pengaruh brand positioning terhadap brand equity; mengetahui dan menjelaskan pengaruh sales promotion terhadap brand equity; mengetahui dan menjelaskan pengaruh brand 
positioning terhadap keputusan pembelian; (4) mengetahui dan menjelaskan pengaruh sales promotion terhadap keputusan pembelian; (5) mengetahui dan menjelaskan pengaruh brand equity terhadap keputusan pembelian.

\section{TINJAUAN TEORI}

\section{Brand Positioning (Pemosisian Merek)}

Brand positioning adalah bagian dari branding strategy yang bertujuan untuk memenangi dan menguasai benak pelanggan melalui produk dan jasa yang ditawarkan. Menurut Gelder (2005) brand positioning adalah suatu cara untuk mendemonstrasikan keunggulan dari suatu merek dan perbedaannya dari kompetitor yang lain. Kartajaya (2009) menyatakan brand positioning sebagai "The strategy for leading your customers credibly", yaitu suatu strategi untuk membangun kepercayaan, keyakinan dan kompetensi bagi konsumen.

Menurut AB Susanto dan Hilmawan dalam Wibowo (2010), pemosisian merek adalah posisi relatif merek kita di antara merek pesaing di dalam persepsi konsumen. Terdapat 5 prinsip yang dapat dipakai untuk melihat efektivitas penempatan posisi merek yaitu nilai, keunikan, kredibilitas, keberlanjutan dan kesesuaian.

1. Nilai; yaitu fokus pada manfaat yang diterima oleh konsumen. Intinya adalah nilai yang diterima oleh pangsa pasar sasaran dari posisi merek yang organisasi atau perusahaan miliki.

2. Keunikan; yaitu membawa sesuatu yang tidak dimiliki oleh pesaing, sehingga posisi merek perusahaan membawa penawaran yang berbeda dibandingkan pesaing.

3. Kredibilitas; yaitu kualitas, kapabilitas, atau kekuatan untuk menimbulkan kepercayaan.

4. Keberlanjutan; yaitu memaksimalkan rentang waktu lamanya menempati posisi dalam persaingan, sehingga pertanyaan utamanya adalah seberapa jauh kita dapat bertahan lama.

5. Kesesuaian; yaitu antara posisi merek perusahaan atau organisasi yang dapat bertahan lama.

\section{Sales Promotion (Promosi Penjualan)}

Sales promotion adalah salah satu aspek dari 5 aspek promotional mix menurut Kotler (2007). Lima aspek dari promotional mix antara lain; advertising (periklanan), 
personal selling (penjualan tatap muka), publicity (publisitas), sales promotion (promosi penjualan), dan direct marketing (pemasaran langsung).

Menurut Hermawan (2012), definisi promosi penjualan sebagai bentuk persuasi langsung melalui penggunaan berbagai insentif yang dapat diatur untuk merangsang pembelian produk dengan segera dan atau meningkatkan jumlah barang yang dibeli konsumen. Melalui promosi penjualan perusahaan dapat menarik konsumen baru, mendorong konsumen membeli dalam jumlah yang lebih besar, menyerang aktivitas promosi pesaing, meningkatkan impulse buying (pembelian tanpa rencana sebelumnya), atau mengupayakan kerjasama yang lebih erat dengan pengecer.

$$
\text { Menurut Hermawan (2012), }
$$
berdasarkan tujuan yang ingin dicapai, promosi penjualan yang dilakukan oleh penjual dapat diklasifikasikan ke dalam 4 (empat) kelompok, yaitu:

1. Costumer promotion (Promosi kepada konsumen); yaitu promosi yang bertujuan untuk merangsang atau mendorong konsumen untuk membeli.
2. Trade promotion (Promosi dagang); promosi penjualan yang bertujuan untuk mendorong para pedagang grosir (wholesalers), pengecer (retailers), eksportir, dan importir untuk memperdagangkan barang / jasa produsen / perusahaan.

3. Sales force promotion (Promosi kepada tenaga penjualan); promosi penjualan yang bertujuan untuk memotivasi para tenaga penjualan.

4. Bussiness Promotion (Promosi bisnis); promosi penjualan yang bertujuan memperoleh konsumen baru, mempertahankan hubungan dengan konsumen, memperkenalkan produk baru, menjual lebih banyak kepada konsumen lama, serta mendidik konsumen.

\section{Brand Equity (Ekuitas Merek)}

Brand equity adalah nilai tambah yang diberikan pada produk dan jasa. Ekuitas merek dapat tercermin dalam cara konsumen berpikir, merasa, dan bertindak dalam hubungannya dengan merek, dan juga harga, pangsa pasar, dan profitabilitas, yang diberikan merek bagi perusahaan (Kotler, Keller 2009:26). Sedangkan ekuitas merek menurut Aaker (dalam Fandy Tjiptono: 2005) adalah 
serangkaian aset dan kewajiban (liabilities)

merek yang terkait dengan sebuah merek, nama, dan simbolnya, yang menambah atau mengurangi nilai yang diberikan oleh sebuah produk atau jasa kepada perusahaan dan atau pelanggan perusahaan tersebut.

Aaker (dalam Fandy Tjiptono: 2005) menjabarkan asset merek yang berkontribusi pada penciptaan ekuitas merek ke dalam empat dimensi, yaitu brand awareness, perceived quality, brand associations, dan brand loyalty. Brand awareness adalah kemampuan konsumen untuk mengenali atau mengingat bahwa sebuah merek merupakan anggota dari kategori produk tertentu. Perceived quality merupakan penilaian konsumen terhadap keunggulan atau superioritas produk secara keseluruhan. Brand associations adalah segala sesuatu yang terkait dengan memori terhadap sebuah merek. Brand loyalty diartikan sebagai pembelian ulang suatu merek secara konsisten oleh pelanggan.

\section{Purchasing Decisions (Keputusan}

\section{Pembelian)}

Menurut Kotler dan Keller (2009), perilaku konsumen akan menentukan proses pengambilan keputusan dalam pembelian. Proses pengambilan keputusan tersebut

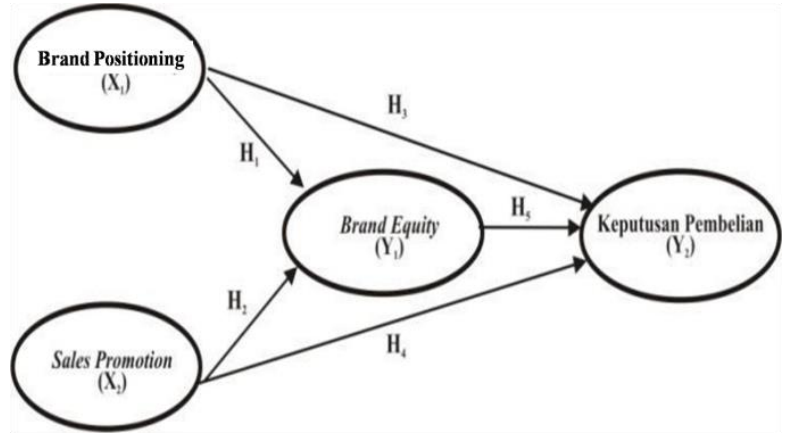

Gambar 1. Model Hipotesis

merupakan sebuah pendekatan penyelesaian masalah yang terdiri atas lima tahap, diantaranya pengenalan masalah, pencarian informasi, evaluasi alternatif, keputusan pembelian, dan perilaku pasca pembelian. Berdasarkan penjelasan tersebut dapat disimpulan bahwa keputusan pembelian merupakan proses penetapan pilihan konsumen melalui berbagai alternatif terhadap produk yang paling disukai.

\section{Model Hipotesis}

Berdasarkan tinjauan pustaka yang telah diuraikan, maka model hipotesis untuk mengukur pengaruh brand positioning dan sales promotion terhadap brand equity dan keputusan pembelian, seperti pada Gambar 1. 


\section{METODE RISET}

Jenis penelitian ini merupakan penelitian kausalitas dengan menggunakan pendekatan kuantitatif.

Pengumpulan data dilakukan dengan menyebarkan angket. Sebanyak 100 orang nasabah Pegadaian Syariah Simpang Patal berpartisipasi sebagai sampel penelitian ini. Teknik pengambilan sampel yang digunakan adalah convenience sampling dengan kriteria responden adalah nasabah Pegadaian Syariah Syariah dan masih aktif mengunakan layanan sampai dengan akhir 2016.

Uji validitas dilakukan dengan mengunakan rumus korelasi Pearson Product Moment dan uji relibialitas dilakukan dengan menggunakan rumus Alpha Cronbach. Keseluruhan item dalam penelitian ini telah valid dan reliabel. Analisis deskriptif dan stuctural equation modeling digunakan sebagai teknik analisis data. Adapun diagram jalur dalam penelitian ini dijelaskan pada Gambar 2.

Berdasarkan diagram jalur pada Gambar 2, persamaan substruktural dari penelitian ini adalah:

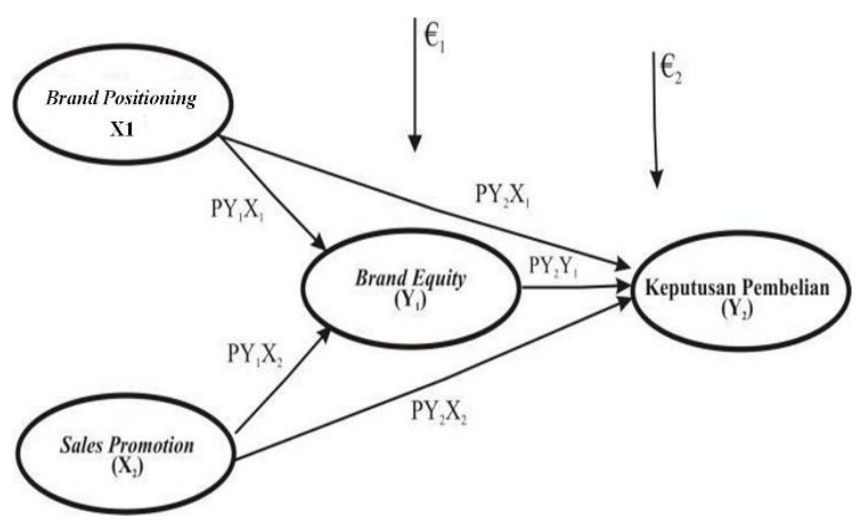

Gambar 2. Persamaan Stuktural

1. Persamaan Substruktural 1

$\mathrm{Y} 1=\mathrm{PY} 1 \mathrm{X} 1+\mathrm{PY} 1 \mathrm{X} 2+€ 1$

2. Persamaan substruktural 2.

$\mathrm{Y} 2=\mathrm{PY} 2 \mathrm{X} 1+\mathrm{PY} 2 \mathrm{X} 2+\mathrm{PY} 2 \mathrm{Y} 1+€ 2$

\section{PEMBAHASAN}

Pada hasil penelitian ini diketahui bahwa mayoritas responden adalah perempuan dengan rentang usia yang dominan adalah antara 26 tahun sampai dengan 45 tahun dan frekuensi transaksi lebih dari 3 kali. Adapun dari sisi pendidikan yang dominan adalah pendidikan menengah atas dan pendidikan tinggi dengan pekerjaan mayoritas adalah ibu rumah tangga dan karyawan.

Pengujian hipotesis menggunakan structural equation modeling (SEM) dengan $\alpha$ pada level 5\%. Tabel 1 menunjukkan hasil perhitungan rata-rata (mean) indikator untuk 
masing-masing variabel. Tabel 2

menunjukkan keseluruhan hasil analisis

structural equation modeling.

Tabel 2.

Nilai Rata-Rata (Mean) Indikator

\begin{tabular}{|c|c|c|c|c|c|}
\hline \multirow[b]{2}{*}{ No } & \multirow[b]{2}{*}{ Variabel } & \multirow[b]{2}{*}{ Indikator } & \multirow[b]{2}{*}{ Kode } & \multicolumn{2}{|c|}{$\begin{array}{l}\text { Nilai Rata-Rata } \\
\text { (Mean) }\end{array}$} \\
\hline & & & & Indikator & $\begin{array}{c}\text { Grand } \\
\text { Mean } \\
\text { Variabel }\end{array}$ \\
\hline \multirow{5}{*}{1.} & \multirow{5}{*}{$\begin{array}{c}\text { Brand } \\
\text { Postioning }\end{array}$} & Nilai & $\mathrm{X} 1.1$ & 4,27 & \multirow{5}{*}{4,30} \\
\hline & & Keunikan & $\mathrm{X} 1.2$ & 4,25 & \\
\hline & & Kredibilitas & $\mathrm{X} 1.3$ & 4,38 & \\
\hline & & Keberlanjutan & $\mathrm{X} 1.4$ & 4,41 & \\
\hline & & Kesesuian & $\mathrm{X} 1.5$ & 4,26 & \\
\hline \multirow{7}{*}{2.} & \multirow{7}{*}{$\begin{array}{c}\text { Sales } \\
\text { Promotion }\end{array}$} & $\begin{array}{l}\text { Kemilau } \\
\text { Emas }\end{array}$ & $\mathrm{X} 2.1$ & 4,13 & \multirow{7}{*}{4,11} \\
\hline & & $\begin{array}{c}\text { Cashback } \\
\text { Biaya Adm }\end{array}$ & $\mathrm{X} 2.2$ & 4,12 & \\
\hline & & $\begin{array}{c}\text { Diskon Jasa } \\
\text { Simpan } \\
\end{array}$ & $\mathrm{X} 2.3$ & 4,14 & \\
\hline & & $\begin{array}{c}\text { Hadiah } \\
\text { Langsung }\end{array}$ & $\mathrm{X} 2.4$ & 4,14 & \\
\hline & & Point of Sales & $\mathrm{X} 2.5$ & 4,05 & \\
\hline & & Agen Emas & $\mathrm{X} 2.6$ & 4,09 & \\
\hline & & $\begin{array}{c}\text { Sahabat } \\
\text { Pegadaian }\end{array}$ & $\mathrm{X} 2.7$ & 4,14 & \\
\hline \multirow{4}{*}{3.} & \multirow{4}{*}{$\begin{array}{l}\text { Brand } \\
\text { Equity }\end{array}$} & $\begin{array}{c}\text { Kesadaran } \\
\text { Merek }\end{array}$ & Y1.1 & 4,17 & \multirow{4}{*}{4,24} \\
\hline & & $\begin{array}{c}\text { Asosiasi } \\
\text { Merek }\end{array}$ & Y1.2 & 4,32 & \\
\hline & & $\begin{array}{l}\text { Persepsi } \\
\text { Kualitas }\end{array}$ & Y1.3 & 4,34 & \\
\hline & & $\begin{array}{c}\text { Loyalitas } \\
\text { Merek }\end{array}$ & Y1.4 & 4,14 & \\
\hline \multirow{5}{*}{4.} & \multirow{5}{*}{$\begin{array}{l}\text { Keputusan } \\
\text { Pembelian }\end{array}$} & $\begin{array}{c}\text { Pengenalan } \\
\text { Masalah } \\
\end{array}$ & Y2.1 & 4,09 & \multirow{5}{*}{4,10} \\
\hline & & $\begin{array}{l}\text { Pencarian } \\
\text { Informasi }\end{array}$ & $\mathrm{Y} 2.2$ & 4,05 & \\
\hline & & $\begin{array}{c}\text { Evaluasi } \\
\text { Alternatif }\end{array}$ & $\mathrm{Y} 2.3$ & 4,06 & \\
\hline & & $\begin{array}{l}\text { Keputusan } \\
\text { Pembelian }\end{array}$ & $\mathrm{Y} 2.4$ & 4,16 & \\
\hline & & $\begin{array}{c}\text { Perilaku } \\
\text { Pasca } \\
\text { Pembelian }\end{array}$ & $Y 2.5$ & 4,18 & \\
\hline
\end{tabular}

Sumber : Kuesioner, diolah (2017)
Berdasarkan Tabel 2 diketahui bahwa indikator keberlanjutan mendapatkan nilai rata-rata (mean) tertinggi $(4,41)$ dari variabel brand positioning. Indikator diskon jasa simpang, hadiah langsung, dan Sahabat Pegadaian mendapatkan nilai rata-rata (mean) tertinggi $(4,14)$ dari variabel sales promotion. Indikator persepsi kualitas mendapatkan nilai rata-rata (mean) tertinggi $(4,14)$ dari variabel brand equity. Indikator perilaku pasca pembelian mendapatkan nilai rata-rata (mean) tertinggi $(4,18)$ dari variabel keputusan pembelian.

Adapun dua persamaan struktural yang dihasilkan oleh Tabel 3 adalah berikut ini :

1 Persamaan Struktural I

$$
\mathrm{Y} 1=1.293 \mathrm{X} 1-0.004 \mathrm{X} 2+0,448
$$

Tabel 3.

Hasil Analisis SEM

\begin{tabular}{|c|c|c|c|c|c|}
\hline $\begin{array}{l}\text { Variabel } \\
\text { Eksogen }\end{array}$ & $\begin{array}{l}\text { Variabel } \\
\text { Endogen }\end{array}$ & $\beta$ & $\begin{array}{c}\text { T } \\
\text { Hitung }\end{array}$ & Sig. & $\begin{array}{c}\text { Ket } \\
\text {. }\end{array}$ \\
\hline $\bar{X} 1$ & $\mathrm{Y} 1$ & 1,293 & 6,672 & $\frac{1}{0,000}$ & $\begin{array}{l}\text { Sig. } \\
(+)\end{array}$ \\
\hline $\mathrm{X} 2$ & & $\begin{array}{l}-\overline{-} \\
0,004\end{array}$ & $-2,870$ & 0,004 & $\begin{array}{l}\text { Sig. } \\
(-)\end{array}$ \\
\hline $\bar{X} 1$ & $\bar{Y} 2$ & $\begin{array}{l}- \\
0,553\end{array}$ & $-0,818$ & 0,413 & $\begin{array}{l}\text { Tdk } \\
\text { Sig. } \\
(-)\end{array}$ \\
\hline $\bar{X} 2$ & & $\begin{array}{l}-\overline{-} \\
0,006\end{array}$ & $-2,898$ & 0,004 & \\
\hline Y1 & & 1,922 & 1,880 & 0,060 & $\begin{array}{l}\text { Tdk } \\
\text { Sig. } \\
(+)\end{array}$ \\
\hline
\end{tabular}

Sumber : Hasil Uji AMOS, diolah (2017) 
Keterangan :

1. Error atau residual persamaan struktural satu adalah 0,448 diperoleh dari $1-0,552$ yang diambil dari Squared Multiple Correlations.

2. Error atau residual persamaan struktural dua adalah 1,104 diperoleh dari 1-(-0,104) yang diambil dari tabel Squared Multiple Correlations.

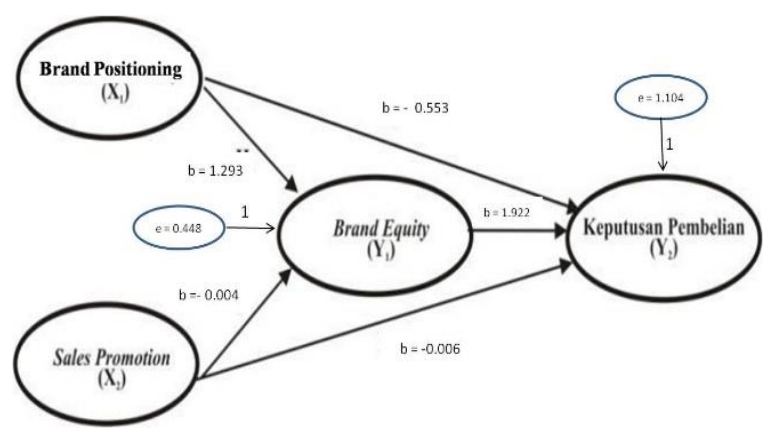

Gambar 3. Koefisien Regresi

Dari kedua persamaan struktural di atas dapat dibentuk diagram koefisien regresi sebagaimana tertera dalam gambar 3 .

Hasil perhitungan pengaruh langsung, pengaruh tidak langsung, dan pengaruh total terdapat pada Tabel 4 berikut ini :

Tabel 4.

Pengaruh Langsung, Tidak Langs ung, dan Total

\begin{tabular}{|c|l|c|c|c|c|}
\hline No & \multicolumn{1}{|c|}{ Jenis Pengaruh } & $\begin{array}{c}\text { Sales } \\
\text { Promotion }\end{array}$ & $\begin{array}{c}\text { Brand } \\
\text { Positioning }\end{array}$ & $\begin{array}{c}\text { Brand } \\
\text { Equity }\end{array}$ & $\begin{array}{c}\text { Keputusan } \\
\text { Pembelian }\end{array}$ \\
\hline $\mathbf{1}$ & Pengaruh Langusng & & & & \\
\hline & Brand Equity & -.004 & 1.293 & .000 & .000 \\
\hline & Keputusan Pembelian & -.006 & -.553 & 1.922 & .000 \\
\hline $\mathbf{2}$ & Pengaruh Tidak Langsung & & & & .000 \\
\hline & Brand Equity & .000 & .000 & .000 \\
\hline & Keputusan Pembelian & -.008 & 2.365 & .000 & .000 \\
\hline $\mathbf{3}$ & Pengaruh Total & & & & .000 \\
\hline & Brand Equity & -.004 & 1.293 & .000 & .000 \\
\hline & Keputusan Pembelian & -.014 & 1.932 & 1.922 & .000 \\
\hline
\end{tabular}




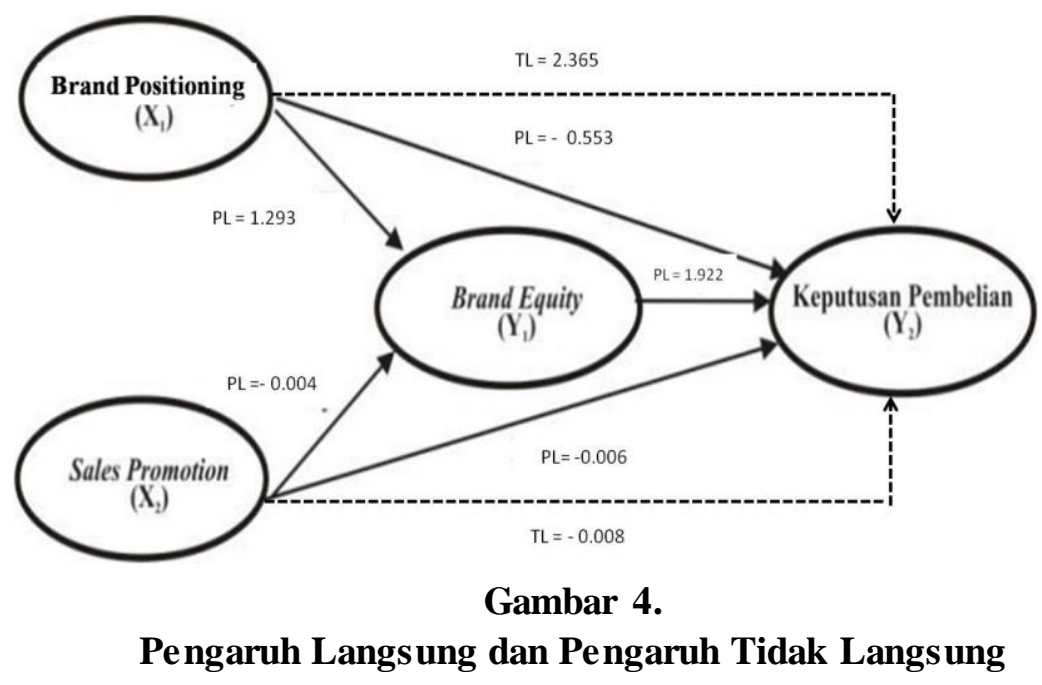

Berdasarkan Tabel 4 dapat dibuat diagram gabungan pengaruh langsung dan tidak langsung, seperti pada Gambar 4.

Keterangan :

PL = Pengaruh langsung, dengan garis penuh (full line)

$\mathrm{TL} \quad=$ Pengaruh tidak langsung, dengan garis putus (dot line)

Berdasarkan Gambar 4 di atas, hasil perhitungan pengaruh tidak langsung dari brand positioning dan sales promotion melalui brand equity menunjukan bahwa brand positioning memilih pengaruh tidak langsung yang lebih besar (sebesar 2.365) daripada sales promotion (sebesar -0,008). Adapun pengaruh langsung brand positioning terhadap keputusan pembelian (sebesar-0,553) lebih kecil daripada pengaruh tidak langsung brand positioning terhadap keputusan pembelian melalui brand equity (sebesar 2.365). Hasil ini menjelaskan bahwa brand equity dalam penelitian ini merupakan variabel intervening.

Sebaliknya berdasarkan Gambar 3 ditemukan bahwa pengaruh langsung sales promotion terhadap keputusan pembelian (sebesar-0,006) lebih besar daripada pengaruh tidak langsung sales promotion terhadap keputusan pembelian melalui brand equity (sebesar -0,008). Hasil ini menjelaskan bahwa brand equity dalam penelitian ini bukan merupakan variabel intervening.

Dari Tabel 3, hasil perhitungan pengaruh total dari brand positioning dan sales promotion terhadap brand equity menunjukan bahwa brand positioning memiliki pengaruh total yang paling besar (sebesar 1.293) daripada 
pengaruh total dari sales promotion $(-0,004)$.

Kemudian hasil perhitungan pengaruh total dari brand positioning, sales promotion, dan brand equity terhadap keputusan pembelian menunjukan bahwa brand positioning memilih pengaruh total yang paling besar $(1,932)$ terhadap keputusan pembelian daripada sales promotion (sebesar -0,014) dan brand equity $(1,922)$.

\section{Diskusi}

Hasil penelitian ini memberikan implikasi, baik secara teoritis maupun manajerial. Hasil penelitian dapat digunakan para peneliti sebagai perhatian dalam meneliti variabel-variabel terkait. Demikian juga secara manajerial penelitian ini dapat dijadikan sebagai acuan manajemen dalam menentukan skala prioritas kebijakan apa yang harus didahulukan.

$$
\text { Penelitian ini bertujuan untuk }
$$
mengetahui pengaruh brand positioning dan sales promotion terhadap brand equity dan keputusan nasabah memilih Pegadaian Syariah. Pengujian ditunjukan melalui hipotesis yang ada sehingga dapat mengetahui bagaimana pengaruh masing-masing variabel terhadap variabel yang lainnya. Adapun pembahasan penelitian ini akan menjadikan setiap hipotesis dan temuan sebagai sudut pandang untuk mengeksplorasi hasil penelitian, baik dari sisi implikasi teoritis maupun implikasi manajerial.

Berdasarkan hasil pengujian statistik yang terdapat pada Tabel 3, diketahui bahwa brand positioning berpengaruh positif dan signifikan terhadap brand equity. Hasil penelitian ini selaras dengan hasil penelitian sebelumnya, dimana brand positioning mempunyai pengaruh positif dan signifikan terhadap brand equity. Adapun penelitian tersebut dilakukan oleh Kusno et.al (2007), Rodrigues et.al (2013), Chen et.al (2016), Jatmiko et.al (2015) dan Qi et.al (2013). Hasil penelitian ini memberikan justifikasi empirik terhadap temuan para peneliti sebelumnya.

Demikian juga berdasarkan Tabel 3, diketahui bahwa sales promotion berpengaruh negatif namun signifikan terhadap brand equity. Hasil penelitian ini selaras dengan penelitian Surahmat et.al (2008) dan Florence et.al(2011), yang juga menemukan hubungan sales promotion mempunyai pengaruh negatif terhadap brand equity. Namun sebaliknya penelitian ini bertentangan dengan penelitian Mongilala (2010), Octaria et.al (2015), dan Salelaw, et.al (2016), yang menemukan 
pengaruh sales promotion berpengaruh positif dan signifikan terhadap brand equity.

Berdasarkan Tabel 3 juga diketahui bahwa brand positioning tidak berpengaruh terhadap keputusan pembelian. Hasil penelitian ini bertentangan dengan studi empiris yang dilakukan oleh Maharani, et.al (2014) dan Jatmiko et.al (2015) dimana penelitian mereka menjelaskan bahwa brand positioning berpengaruh signifikan terhadap keputusan pembelian.

Sebaliknya Tabel 3 juga menunjukan bahwa sales promotion berpengaruh signfikan terhadap keputusan pembelian, namun pengaruhnya negatif. Penelitian ini menguatkan penelitian Surahmat et.al (2008) dan Octaria et.al(2015), yang juga menemukan hasil yang sama. Namun sebaliknya bertentangan dengan hasil penelitian Fauziah (2015) dan Shreshta (2015), yang menemukan sales promotion berpengaruh positif dan signifikan terhadap keputusan pembelian.

Berdasarkan Tabel 3 diketahui bahwa brand equity tidak berpengaruh terhadap keputusan pembelian namun hubungannya positif. Temuan penelitian ini bertentangan dengan penelitian yang dilakukan Surahmat et.al (2008), Octaria et. al.(2015) Jatmiko et.al
(2015), Vukasovic (2013), Heidarian et.al (2015), dan Siali et.al (2016), yang menemukan bahwa terdapat hubungan yang kuat antara brand equity dan keputusan pembelian.

Dari Gambar 3 diketahui brand equity merupakan satu-satunya faktor positif yang mempengaruhi keputusan pembelian. Sedangkan faktor lainnya, yaitu brand positioning dan sales promotion berpengaruh sebaliknya terhadap keputusan pembelian. Hal ini menunjukan bahwa peningkatan ekuitas merek dapat mendorong keputusan pembelian nasabah. Sebaliknya upaya brand positioning dan program sales promotion yang dijalankan selama ini terbukti belum berhasil mendorong keputusan pembelian nasabah.

Dalam menyusun program peningkatan ekuitas merek perusahaan harus memperhatikan dimensi yang membentuknya. Dimensi yang paling dominan dalam pembentukan ekuitas merek adalah brand awareness, diikuti oleh brand loyalty. Hasil ini mengindikasikan bahwa upaya yang dilakukan oleh perusahaan untuk meningkatkan kesadaran dan loyalitas nasabah terbukti efektif.

Adapun indikator yang paling dominan dalam dimensi brand awareness adalah Pegadaian Syariah melayani pinjaman sistem 
gadai yang sesuai syariah. Begitupun indikator yang paling dominan dalam dimensi brand loyalty adalah Pegadaian Syariah adalah pilihan utama solusi kebutuhan dana cepat sesuai syariah. Kondisi ini menunjukan bahwa tingkat kesadaran nasabah bahwa Pegadaian Syariah melayani pinjaman sistem gadai sesuai syariah tinggi. Selain itu juga mengkonfirmasi bahwa Pegadaian Syariah menjadi solusi utama bagi nasabah jika mereka membutuhkan dana cepat dan sesuai syariah.

Pihak manajemen harus mengevaluasi upaya yang dilakukan terkait strategi brand positioning. Hal ini dikarenakan upaya tersebut belum mampu mendorong nasabahmemutuskan untuk memilih Pegadaian Syariah. Upaya terkait brand positioning, diantaranya melalui program komunikasi beberapa main statement berikut ini; solusi tepat kebutuhan dana cepat sesuai syariah dan benar caranya berkah hasilnya, serta program statement di antaranya milik negara, syarat mudah, proses aman, cepat, mudah, setoran angsuran pinjaman ringan, dan terpercaya belum mampu mempengaruhi nasabah memilih bertransaksi di Pegadaian Syariah Simpang Patal.
Adapun indikator yang paling dominan dalam brand positioning adalah prinsip kredibilitas. Prinsip kredibilitas dijelaskan melalui dua item pertanyaan yaitu barang jaminan ditaksir optimal dan barang jaminan aman dan diasuransikan ternyata adalah faktor yang dominan membentuk brand positioning perusahaan. Oleh karena itu, manajemen harus menjadikan kedua hal ini menjadi skala prioritas untuk diperhatikan dalam merancang strategi dan program brand positioning perusahaan.

Demikian juga program sales promotion harus dievaluasi oleh manajemen. Program sales promotion yang selama ini dilakukan belum mampu mempengaruhi keputusan nasabah memilih Pegadaian Syariah. Program sales promotion berikut ini; undian kemilau emas, cashback biaya administrasi, diskon jasa simpan, hadiah langsung, point of sales berupa bazar emas lelang, pameran, seminar penjualan, program agen emas, dan program Sahabat Pegadaian, terbukti secara bersama-sama belum mampu mempengaruhi keputusan pembelian nasabah.

Program sales promotion yang dilaksanakan Pegadaian Syariah selama ini belum mampu mendorong keputusan pembelian 
disebabkan image produk gadai selama ini masih kurang baik di masyarakat, tak terkecuali produk gadai syariah. Masyarakat cenderung masih malu berhubungan dengan Pegadaian. Kondisi psikologis masyarakat ini membuat beragam kegiatan program sales promotion yang notabene bertujuan untuk mendorong nasabah agar melakukan transaksi segera dalam jangka pendek tidak berhasil.

Selain itu, karakteristik produk gadai adalah untuk memenuhi kebutuhan nasabah yang mendesak dengan menitipkan barang jaminan. Masyarakat yang menjadi objek kegiatan sales promotion tidak langsung tertarik mengunakan produk gadai dikarenakan mereka belum membutuhkan pada saat mengetahui program tersebut.

Adapun indikator yang paling dominan dari sales promotion adalah program hadiah langsung, diikuti program point of sales dan cashback biaya administrasi. Hal ini menegaskan bahwa perusahaan dalam merancang program promosi penjualan dapat menjadikan ketiga kegiatan ini sebagai skala prioritas.

Berdasarkan Gambar 3 diketahui bahwa brand positioning adalah faktor positif yang dominan mempengaruhi brand equity, sebaliknya sales promotion berpengaruh negatif. Temuan penelitian ini menjelaskan bahwa upaya terkait brand positioning yang dilakukan mampu mendorong peningkatan nilai ekuitas merek perusahaan. Sebaliknya program sales promotion yang dilaksanakan selama ini belum efektif mempengaruhi peningkatan ekuitas merek.

Kondisi ini seyogyanya menjadi perhatian manajemen dalam merancang strategi dan program terkait pembangunan ekuitas merek perusahaan. Manajemen dapat terus mempertahankan prinsip-prinsip brand positioning yang sudah terbentuk melalui main statement dan program statement yang sudah ada selama ini, karena terbukti efektif mempengaruhi peningkatan ekuitas merek perusahaan.

Sebaliknya perlu dilakukan evaluasi terhadap kegiatan sales promotion, karena belum mampu memberi pengaruh terhadap peningkatan ekuitas merek. Kegiatan sales promotion yang selama ini kurang berpengaruh, seperti Program Undian Kemilau Emas dan Program Sahabat pegadaian, sebaiknya dilakukan dievaluasi mendalam.

Berdasarkan Gambar 4 diketahui bahwa pengaruh tidak langsung brand positioning 
terhadap keputusan pembelian melalui brand equity bernilai positif. Sebaliknya pengaruh tidak langsung sales promotion bernilai negatif. Hal ini menjelaskan bahwa kebijakan terkait strategi brand positioning dan peningkatan ekuitas merek dapat dilakukan secara bersamasama dalam rangka mendorong keputusan nasabah agar memilih bertransaksi di Pegadaian Syariah. Sebaliknya kegiatan sales promotion dan brand equity yang dilakukan secara bersama berpengaruh sebaliknya terhadap keputusan pembelian.

Berdasarkan Gambar 4 diketahui bahwa pengaruh tidak langsung brand positioning terhadap keputusan pembelian lebih besar dan bernilai positif daripada pengaruh langsung. Kondisi ini menjelaskan bahwa strategi brand positioning tidak efektif untuk langsung mendorong keputusan pembelian nasabah. Namun, strategi brand positioning sangat efektif mendorong keputusan nasabah jika terlebih dahulu dimaksudkan untuk meningkatkan ekuitas merek. Melalui peningkatan ekuitas merek inilah secara tidak langsung brand positioning sangat efektif mempengaruhi keputusan pembelian.
Berdasarkan Tabel 4 diketahui bahwa pengaruh langung dan tidak langsung sales promotion terhadap keputusan pembelian bernilai negatif. Namun, pengaruh langsung bernilai lebih besar daripada pengaruh tidak langsung. Temuan ini mengindikasikan bahwa program sales promotion secara langsung dan tidak langsung tidak efektif mempengaruhi keputusan pembelian. Namun, besaran pengaruh program sales promotion lebih besar secara langsung daripada tidak langsung melalui brand equity.

\section{KESIMPULAN DAN SARAN}

\section{Kesimpulan}

Berdasarkan hasil analisis dan pembahasan, maka diperoleh kesimpulan yaitu:

1. Brand positioning berpengaruh positif dan signifikan terhadap brand equity. Hal tersebut menunjukkan bahwa indikator pembentuk brand positioning dapat membantu membangun ekuitas yang baik dari sebuah merek.

2. Sales promotion berpengaruh negatif dan signifikan terhadap brand equity. Hal tersebut menunjukkan bahwa indikatorindikator pembentuk sales promotion 
seperti undian kemilau emas, cashback biaya administrasi, diskon jasa simpan, hadiah langsung, point of sales, agen emas dan program Sahabat Pegadaian, yang dilakukan oleh Pegadaian Syariah tidak mampu mendukung penciptaan brand equity.

3. Brand Positioning tidak berpengaruh terhadap keputusan pembelian. Hal tersebut berarti indikator prinsip nilai, prinsip keunikan, prinsip kredibilitas, prinsip keberlanjutan dan prinsip kesesuaian kesempurnaan sebagai pembentuk brand positioning tidak dapat mendorong pembelian konsumen.

4. Sales Promotion berpengaruh negatif dan tidak signifikan terhadap keputusan pembelian. Hal tersebut menunjukkan bahwa undian kemilau emas, cashback biaya administrasi, diskon jasa simpan, hadiah langsung, point of sales, agen emas dan program Sahabat Pegadaian, yang dilakukan oleh Pegadaian Syariah tidak mampu mendorong keputusan seorang konsumen untuk membeli.

5. Brand equity tidak berpengaruh terhadap keputusan pembelian konsumen. Hal ini menunjukkan bahwa nilai lebih yang dimiliki sebuah merek belum mampu

mendorong keputusan pembelian

konsumen.

\section{Saran}

Berdasarkan hasil penelitian, maka diberikan beberapa saran untuk melengkapi hasil penelitian ini yaitu sebagai berikut:

1. Pegadaian Syariah disarankan untuk lebih memperhatikan pembentukan brand positioning terutama pada indikator prinsip keunikan dan prinsip kesesuaian yang mendapatkan nilai rata-rata paling rendah. Terkait prinsip keunikan, hal yang dapat dilakukan adalah dengan menerapkan standarisasi pelayanan yang menjadikan kecepatan layanan, kemudahan persyaratan, dan fleksibilitas sistem transaksi sebagai skala prioritas. Demikian juga dengan prinsip kesesuain, hal yang dapat dilakukan adalah merancang standarisasi produk dan standarisasi layanan yang sesuai dengan sistem syariah dan juga senantiasa meningkatkan pemahaman dan kompetensi terkait syariah pada para karyawan.

2. Pegadaian Syariah sebaiknya melakukan evaluasi terhadap program sales 
promotion yang selama ini dilaksanakan, mengingat kegiatan sales promotion yang dilakukan terbukti berpengaruh negatif dan tidak signifikan terhadap keputusan pembelian konsumen. Kegiatan sales promotion yang kurang memberikan kontribusi bagi terciptanya transaksi, seperti program undian kemilau emas, program Sahabat Pegadaian, dan agen emas, sebaiknya ditiadakan. Pegadaian Syariah dapat lebih fokus pada kegiatan sales promotion yang memiliki pengaruh dominan, seperti; hadiah langsung, kegiatan point of sales, dan cashback biaya administrasi.

3. Penelitian selanjutnya diharapkan dapat menggunakan objek penelitian yang berbeda dengan ruang lingkup populasi yang lebih luas dan sampel yang lebih banyak agar dapat memberikan hasil yang lebih baik. 
Analisis Brand Equity... (Nedi Y ansah, Zakaria Wahab \& Muchsin Saggaf Shihab)

\section{DAFTAR PUSTAKA}

Chen JL, Chen TY. 2016. Using Brand Positioning to Enhance Consumers 'Loyalty in Participatory Sport Event (Journal). Soochow Journal of Economics and Business

Fauziah A. 2015. Pengaruh Brand Personality dan Sales Promotion terhadap Puchase Decision Produk Maybelline Studi Pada Mahasiswi S1 Universitas Brawijaya (Jurnal). Fakultas Ekonomi dan Bisnis, Universitas Brawijaya (tidak dipublikasikan).

Gelder, S.V. 2005. Global Brand Strategy. London: Kogan Page.

Hiedarian E, Kariznoee, Bijandi M. 2015. The effect of brand equity on consumer purchasing behaviorCase study: Food famous brands in Mashhad Industrial Town (Journal). 2015. Applied mathematics in Engineering, Management and Technology. Pakistan.

Jatmiko, Setyawati RL, 2015.Pengaruh Brand Positioning dan Brand Equity Terhadap Keputusan Pembelian Sepda Motor Yamaha (Jurnal). Fakultas Ekonomi, Universitas Indonesia Unggul.

Kusno F, Radityani A, Kristanti M. 2007. Analisa Hubungan Brand Strategy Yang Dilakukan Goota Japanese Charcoal Grill and Café dan Brand Equity Yang Sudah Diterima Konsumen (Jurnal).Program Studi Manajemen Perhotelan, Universitas Kristen Petra.

Kartajaya, H. 2009. Brand Operation. Jakarta: Esensi Erlangga Group.

Hermawan, A. 2012. Komunikasi Pemasaran. Jakarta: Erlangga.

Kotler, P. \& Keller, K. L. 2009. Manajemen Pemasaran (Edisi 13). Terjemahan oleh: Bob Sabran, MM. Jakarta: Erlangga.

Maharani C, Andari R, Andrianto T, 2014. Pengaruh Brand Positioning Wonderful Indone sia Terhadap Keputusan Wisatawan Mancanegara Untuk Berkunjung ke Indonesia. Jurnal Tourism and Hospitality Essentially (THE). Program Studi Manajemen Pariwisata, Universitas Pendidikan Bandung.

Merunka D, Guizani H, Florence VP. 2011. The impact of brand personality and Sales Promotions on brand equity (Journal). Journal of Business Research. France.

Nigam A, Kaushik R. 2011. Impact of Brand Equity on Customer Purchase Decisions: An Empirical Investigation with Special Reference to Hatchback Car Owners in Central Haryana. IJCEM International Journal of Computational Engineering \& Management.

Octaria R, Kumadji S, dan Hidayat K. 2015. Pengaruh Brand Personality dan Sales Promotion terhadap Puchase Decision Produk Maybelline Survey pada pengguna Produk Wardah di Universitas Brawijaya Malang (Jurnal). Fakultas Ekonomi dan Bisnis, Universitas Brawijaya (tidak dipublikasikan).

Qi G, Dandan L. 2013.The Effect of Brand Position on Consumer Choices of Luxury Brands: A Cross - Cultural Study Between British and Chinese Consumers (Jurnal). Canadian Academy of Oriental and Occidental Culture. Canada. 
Rodrigues SCI, Menegazzo FW, Chaves SPE. 2013. Brand Loyalty Influence Factors: Positioning and Brand Identity Comparison (Jurnal). Asian Journal of Bussiness and Management Sciences, FHO - Uniaras.

Salelaw, Singh ATG. 2016. The Impact of Sales Promotion on Brand Equity: The Case ofBrewery Industry (Journal). Journal of Marketing and Consumer Research, An International Peer-reviewed Journal. India.

Shresta A. 2015. Effects of Sales Promotion on Purchasing Decision of Costumer a Case Study of Baskin Robbins Ice-Cream Franchise Thailand (Thesys). Bangkok University. Thailand.

Siali F, Jiayi P, Shakur AM, Ya'kob AS. 2016. Relationship between Brand Equity and Consumer Purchase Decision: A Case of an International Brand of Foorwear (Journal). International Journal of Service Management and Sustainability (IJSMS). Malaysia.

Susanto AB, Widjanarko, Himawan. 2004. Power Branding: Membangun Brand yang Legendaris.Jakarta: Mizan.

Tjiptono, F. 2005. Brand Mangement \& Strategy (Edisi 1). Yogyakarta: Andi Ofset

Vukasovic T. 2013. Managing Consumer-Based Brand Equity in Higher Education (Journal). International School for Social Bussiness Studies. Slovenia.

Wibowo AW. 2010. Analisis Pengaruh Brand Identity dan Brand Positioning terhadap Pembentukan Brand Image Perusahaan Asuransi Studi Kasus PT. Asuransi Bumi Putera 1967 (Tesis). Program Studi Manajemen Fakultas Ekonomi, Universitas Indonesia (Tidak dipublikasikan).

Wisesa, SA. 2011. Political Branding \& Public Relations. Jakarta: PT. Gramedia Pustaka Utama.

Zuliyarso Z, Hidayat W, EP. Apriyatni. 2013. Effect Brand Equity and Promotion to Purchasing Decision of Honda Motorcycle (Jurnal).Program Studi Sosial Politik, Universitas Diponegoro. www.marketing.co.id/membangundanmengelola-brandequity/diakses 10 Januari 2017. http://www.tesismars.co.cc/2008/12/brand-equity-rumah-sakit.html diakses 15 Januari 2017 https://www.mis.pegadaian.co.id/ diakses 25 April 2017. http://beritasore.com/2017/01/08/2-200-perusahaan-lakukan-bisnis-gadai/ diakses 16 Juli 2017. 